\title{
BELIEF AND JUDGMENT.
}

Psychologie de la croyance en l'immortalité. C.-J. Wyjaends Francken. Revue Philosophique, LVI., 272-282.

This article is a psycho-genetic study of the belief in personal immortality. This belief may be either psychologico-philosophic in character, or it may be purely religious. Three chief sources for it are pointed out: first, the passion for life; second, the power of the imagination as manifested in dreams; and third, the so-called moral motive. Of these three sources the first is by far the most important. 'The need of personal preservation,' writes the author, ' is one of our strongest instincts; it even crosses the tomb - for the desire for immortality is only one form of manifestation of the search for personal preservation.'

A comparative study of religions reveals the fact that the belief in immortality seems unable to maintain itself upon purely philosophical or ethical considerations, but requires some affective impetus as an essential condition of its existence. It is prevalent only where there exists a strong desire to continue one's personal existence after death. Desire and hope, however, although they form the principal source of the belief in immortality, do not constitute its sole ground. Phenomena of the nature of dreams may very readily give rise to the conception of a soul existing independently of the body and surviving bodily death.

The third motive of the belief in immortality is what the author terms the moral motive. As moral retribution is obviously not perfect in this life, the moral sense saves itself by taking refuge in the postulate of a future life in which the demands of justice will be satisfied. This hope of remuneration in a future life is not a purely egoistic sentiment; it is simply an application of the law of causality to the moral sphere, and is for many persons a postulate of their moral mode of conceiving the universe. To this is sometimes added another moral motive, the desire for moral perfection. We have now no longer desire for mere continued existence of almost any kind, but desire primarily for a life in which there will be possible a realization of the moral ideal.

Belief in immortality is closely allied to the belief in God, and in some cases the two seem to be mutually interdependent. This is natural, as they are both found to have arisen from the same ultimate sources.

The paper is interesting chiefly as an illustration of the increasing 
tendency among psychologists to discover in the will to live the efficient cause of religious manifestations.

BRYN MAWR COLLEGE.

Elisabeth F. Hutchin.

La logique et l'expérience. FÉLIx LE Dantrc. Revue Philosophique, Janvier, I904.

Biology, from its deterministic and evolutionary point of view, regards the laws of thought as the hereditary résumé of ancestral experience, during thousands of years of rubbing against the external world. It is infinitely probable, thanks to natural selection, that thought is adequate to the phenomena which have met our ancestors; but we cannot attribute to it any absolute validity. This view is in opposition to such as that of Poincaré, who, in La Science et l'Hypothese, speaks of the mind as of a tool of a superior sort, with laws of functioning absolute and invariable. The difference between the two views is clearly seen in relation to the group of questions associated with non-Euclidean geometry. Poincaré grants here to experience that it guides the mind to the 'most advantageous' among many 'conventions' of its free activity; but, consonant with this free activity, he holds to an inner core of principles of thought which are absolute. But he cannot justify his distinction between an empirical and an a priori part in geometry. In another world, our logic would be different, as would also the so-called conventions in regard to space.

The character of our sense-knowledge is to be inferred from the very principle of natural selection - it does not deceive, but it is not of the absolute essence of things; it is relative to the preservation of life. It is from experience of this sort, not from that of scientific knowledge, that the laws of thought have been built up. We have gained the so-called ideal conceptions of geometry just because of the imperfection of our means of personal observation. The surface of a lake seems a plane; the tiles of a house, forming irregular lines to close observation, appear at some distance to make perfectly straight parallels.

The article is of interest in relation to the recent English and American discussions along pragmatic lines.

YAIE UNIVERSTYY.

L. A. Weigle.

The Disjunctive Judgment. G. R. T. Ross. Mind, 1903, N. S., XII., 498-501.

The disjunctive judgment in the form $A$ is either $B$ or $C$, is used in many cases where $B$ and $C$ are related, but by no means mutually 